\title{
Minerales en nuestro ambiente
}

1. DESODORANTE: Incluye aluminio y el envase es hecho de

2. CREMA DENTAL: Incluye fluorita, barita y calcita. E

3. VASOS PARA BEBER: Incluye feldespato,

silice y ceniza de sodio.

IIMPSDOR ABRASNO: Incluye slice o calcita. LAFZ LABIAL Y MAQUILLAJE: Incluye productos d

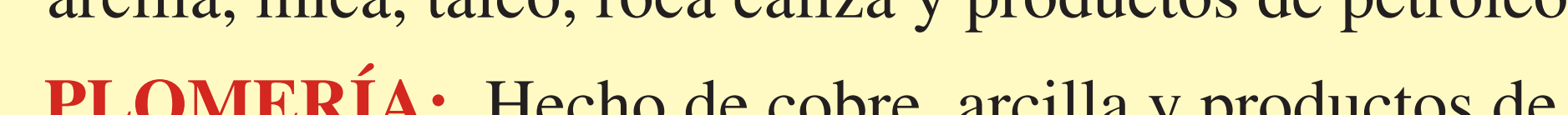
ALFOMBRAS: Incluye roca caliza, productos de

STICAS DE DUCHA: Contiene productos

MASEAA: Hecha de arcillas y minerales metálicos para pigmentos en vidriados.

CHAMPU DE LA CASPA: Incluye alquitrán de carbén

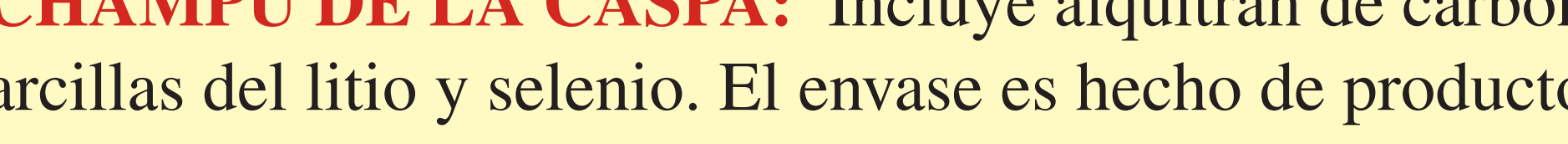
de pertroleo.

12. ESPEJO: Incluye el feldespato, silice y plata.

GRTOS: Incluye hierro, níquel y cromo.

taLDOSAS: Hecho de arc
talco, pigmentos minerales.

de petróleo y los boratos.

1. COMPUTADORA: Incluye oro, silice, níquel, aluminio, cinc, hierro, productos de perfoleo, y cerca de treinta otros (19)

Incluye grafito y arcillas.

y productos de petróleo. (n)

PLUMAS: Incluye roge
arcillas, silice y talco.

Cím

.

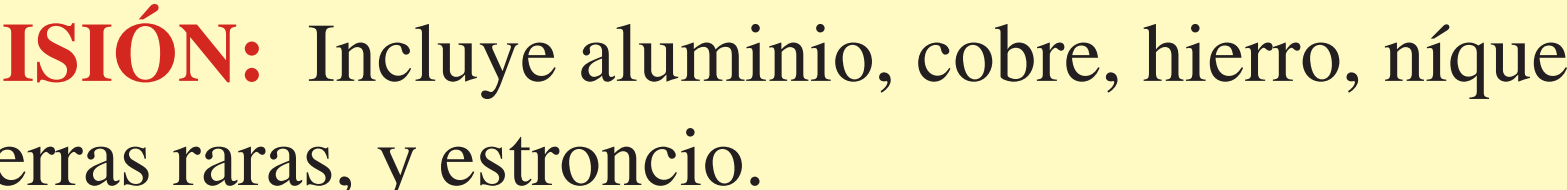

ESTEREOFÓNICO: Inc

the oro, hierro, níquel, berilio

DISCO COMPACTO: Incluye aluminio y productos de

CAJÓN DE METAL: Incluye hierro y níquel. El ajuste de

ALFOMBRA: Incluye roca caliza, productos de petróleo

y selonio.

calcio y mica.
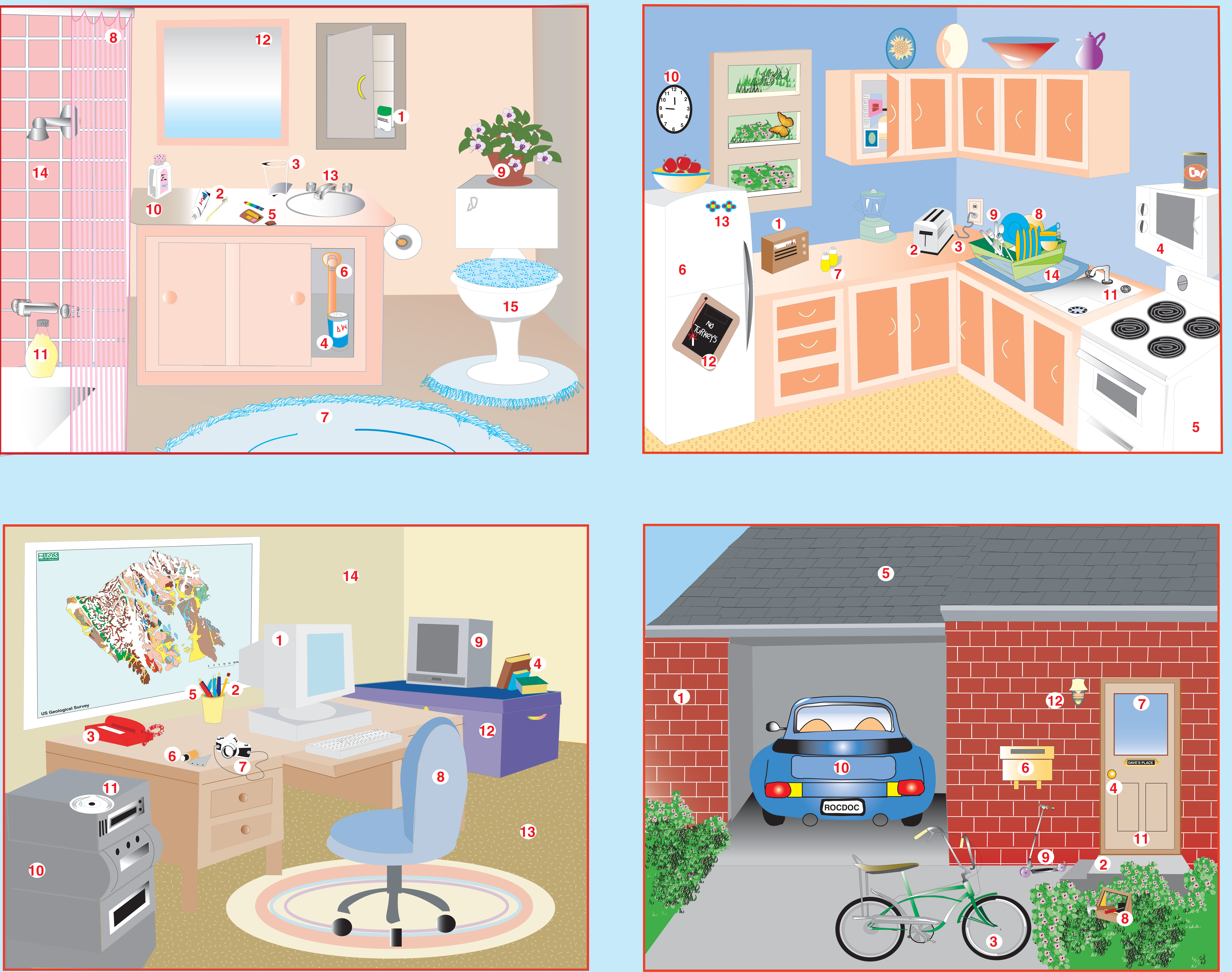

1. RADIO: Incluye aluminio, cobre, hierro del oro y productos

T TOSTADOR: Incluye cobre, hierro, níquel, mica, cromo
y productos de petroleo y productos de petroleo.

CABLEADO ELÉCTRICO: Incluye cobre, aluminio

4. MICROONDA: Incluye cobre, oro, hierro, níquel y silice.

5. ESTUFA: Incluye aluminio, cobre, oro, hierro, níquel y silice.

6. REFRIGERADOR: Incluye aluminio, cobre, hierro, níquel.

ductos de petróleo y cinc.

7. SAL DE LA MESA: Incluye halita; la sal ligera se
puede hacer de silvita. Se ha agregado yodo a la mayor

8. PLATOS: Incluye arcillas, silice y feldespato.

9. CUCHILLERÍA: Incluye hierro, níquel, plata y cromo.

10. RELÓJ: Incluye hierro, níquel, productos de petróleo y silitec

11. FREGADERO DE ACERO INOXIDABLE: Incluye hierto

12. PriquRRel. InA: Incluye arcillas. La tiza incluye roca caliza o
productos de petroleleo.

3. IMAN: Incluye cobalto.

14. ESTANTE DE PLATO: Hecho de productos de petróleo.

1. LADRILLOS: Incluye grafto, arcillas y silice.

2. PASO CONCRETO: Incluye yeso, hierro, la roca caliza,
arcillas y silice.

3. BICICLETA:
de petróleo.

4. BOTÓN DE LA PUERTA: Incluye cobre y cinc,
que hacen latón

5. RIPIAS: Incluye productos de petróleo y arcillas.

6. BUZÓN: Incluye cobre y cinc, que hacen latón

7. VENTANAS: Incluye la silice, feldespato, carbonato de sodio
anhidro, carbón y sal

8. HERRAMIENTAS: Incluye hierro y níquel.

9. MONOPATIN: Incluye aluminio, calcita, mica, níquel,
productos de petróleo, arcillas, silice y talco.

10. AUTOMÓVIL: Incluye aluminio, baritina, aclicita hierro,
plomo, mica, niquel, productos de petroleo, arcillas, plomo, mica, nithe
silice y cinc.

11. PINTURA: Incluye titanio, yeso, baritina y azufre.

12. LUZ Y ACCESORIO: Incluye tungsteno, molibdeno,
aluminio, silice, cobre y cinc. 